\title{
Detection of Menaquinone-6 and a Novel Methyl-substituted Menaquinone-6 in Campylobacter jejuni and Campylobacter fetus subsp. fetus
}

\author{
By GEORGE M. CARLONE ${ }^{*} \dagger$ AND FRANK A. L. ANET \\ ${ }^{1}$ Department of Microbiology and ${ }^{2}$ Department of Chemistry and Biochemistry, University of \\ California at Los Angeles, Los Angeles, California 90024, U.S.A.
}

(Received 8 April 1983; revised 16 July 1983)

\begin{abstract}
Menaquinone-6 (2-methyl-3-farnesyl-farnesyl-1,4-naphthoquinone) and a methyl-substituted menaquinone-6 (2,[5 or 8]-dimethyl-3-farnesyl-farnesyl-1,4-naphthoquinone) were the major isoprenoid quinones found in membrane preparations of Campylobacter jejuni and Campylobacter fetus subsp. fetus. By reverse-phase high-performance liquid chromatography (HPLC) and thin-layer chromatography (TLC) the faster-eluting menaquinone- 6 co-chromatographed with a menaquinone- 6 standard. The identity of menaquinone- 6 was confirmed by UV spectrophotometry, mass spectrometry and nuclear magnetic resonance (NMR) analysis. The slower-eluting methyl-substituted menaquinone- 6 co-chromatographed with a menaquinone-7 standard by reverse-phase TLC but eluted between menaquinone- 6 and menaquinone-7 standards by HPLC. The UV spectrum of the methyl-substituted menaquinone- 6 did not correlate with either authentic menaquinone or demethylmenaquinone. Mass spectra showed an increase of 14 mass units when compared to menaquinone- 6 , and indicated that a methyl substituent was on the naphthoquinone nucleus. NMR spectra confirmed the presence of a methyl substituent at a peri position (carbon-5 or -8 ) on the benzenoid ring.
\end{abstract}

\section{INTRODUCTION}

Respiratory quinones are a class of isoprenoid lipids separated on the basis of structural differences into naphthoquinones and benzoquinones (Collins \& Jones, 1981). Naphthoquinones can be further separated into two types, phylloquinones (2-methyl-3-phytyl-1,4naphthoquinone), which are found predominantly in green plants and in bacteria (Collins \& Jones, 1981; Langemann \& Isler, 1965), and menaquinones (2-methyl-3-polyprenyl-1,4naphthoquinone), which are widely distributed in nature.

Menaquinones of bacteria are lipophilic components of the cytoplasmic membrane which undergo reversible oxidation and reduction to form a quinone or hydroquinone, respectively (Kroger, 1980; Kroger \& Dad'ak, 1969; Taber, 1980). In bacteria they play important roles in the transfer of electrons in the respiratory chain (Bentley \& Meganathan, 1982; Taber, 1980), and may function in oxidative phosphorylation and active transport (Collins \& Jones, 1981; Taber et al., 1981). Menaquinones are also associated with the reduction of fumarate in microorganisms capable of using fumarate as a terminal electron acceptor (Kroger, 1980; Taber, 1980; Thauer et al., 1977). Demethylmenaquinones (DMK) appear to be interchangeable with menaquinones for fumarate reduction, whereas ubiquinones are ineffective (Hollander, 1981).

In Campylobacter jejuni and $C$. fetus subsp. fetus, microaerophilic pathogens of man and animals (Smibert, 1981), fumarate may serve as a terminal electron acceptor (Carlone \& Lascelles, 1982). Both species have low- and high-potential forms of cytochrome $c$ and cytochrome $b$ and an assortment of membrane enzymes including formate dehydrogenase and

† Present address: 1054-1 Noble Vines Drive, Clarkston, GA 30021, U.S.A.

Abbreviations: Acetone $d_{6}$, deuterated acetone; DMK, demethylmenaquinone; MK- $n$, menaquinone with $n$ isoprene units. 
fumarate reductase (Carlone \& Lascelles, 1982; Harvey \& Lascelles, 1980; Hoffman \& Goodman, 1982). Menaquinone isoprenologues associated with these organisms have not been clearly defined and the objective of this investigation was to characterize the respiratory quinones in $C$. jejuni and $C$. fetus subsp. fetus, grown under a microaerobic atmosphere containing hydrogen.

\section{METHODS}

Organisms and cultural conditions. Stock cultures of C. jejuni (ATCC 29428) and C. fetus subsp. fetus (ATCC 27374) were maintained in fluid thioglycolate medium (BBL) and were subcultured weekly. Working cultures were derived from 24 - and 48 -h thioglycolate cultures, respectively, with $1.0 \%$ inocula. Campylobacter jejuni working cultures were grown at $37^{\circ} \mathrm{C}$ and C. fetus subsp. fetus at $30^{\circ} \mathrm{C}$.

Cells were grown in campylobacteria formate/fumarate broth composed of the following, per litre: $10 \mathrm{~g}$ peptone (Difco), $10 \mathrm{~g}$ tryptone (Difco), $10 \mathrm{~g}$ yeast extract (Difco) and $0 \cdot 1 \mathrm{~g}$ sodium bisulphite. Carbon sources were added to the medium before sterilization to a final concentration of $10 \mathrm{mM}$ for sodium formate and $50 \mathrm{~mm}$ for potassium fumarate; the $\mathrm{pH}$ was adjusted to 7.2 with $10 \mathrm{M}-\mathrm{KOH}$. The cultures were in $200 \mathrm{ml}$ volumes, in $500 \mathrm{ml}$ flasks, in an atmosphere containing (by vol.) approximately $5 \% \mathrm{O}_{2}, 10 \% \mathrm{CO}_{2}, 30 \% \mathrm{H}_{2}$ and the balance $\mathrm{N}_{2}$. The inoculated flasks were placed into GasPak jars with the GasPak generating system without a catalyst (BBL) to provide this atmosphere, and the jars were shaken for $24 \mathrm{~h}$ on a gyratory shaker at 200 r.p.m.

Preparation of membrane fractions. Cells were harvested during late-exponential phase ( 22 to $26 \mathrm{~h}$ ) by centrifugation at $4000 \mathrm{~g}$ for $20 \mathrm{~min}$ at $4{ }^{\circ} \mathrm{C}$ and then washed twice in $0 \cdot 1$ vol. $40 \mathrm{mM}$-Tris/ $\mathrm{HCl}$ buffer, $\mathrm{pH} 7 \cdot 5$, and centrifuged at $12000 \mathrm{~g}$ for $10 \mathrm{~min}$. Pellets were pooled and resuspended in $1 \mathrm{ml}$ buffer per $100 \mathrm{ml}$ culture. Cell-free extracts were prepared by two passages of cells through a French pressure cell $\left(845 \mathrm{~kg} \mathrm{~cm}^{-2}\right)$ with the addition of DNAase and RNAase $\left(10 \mu \mathrm{g} \mathrm{ml}^{-1}\right)$.

Cell debris and unbroken cells were removed by centrifugation at $12000 \mathrm{~g}$ for $10 \mathrm{~min}$, and the supernatant fluid was centrifuged at $126000 \mathrm{~g}$ for $90 \mathrm{~min}$ at $4{ }^{\circ} \mathrm{C}$. The pellets were washed once with $40 \mathrm{mM}$-Tris/ $\mathrm{HCl}$ buffer, $\mathrm{pH} 7 \cdot 5$, at $0{ }^{\circ} \mathrm{C}$ and suspended in this buffer containing $20 \%(\mathrm{v} / \mathrm{v})$ glycerol with a polytetrafluoroethylene tissue homogenizer. The suspension was adjusted to contain 5 to $10 \mathrm{mg}$ membrane protein $\mathrm{ml}^{-1}$. This crude membrane fraction was kept at $0^{\circ} \mathrm{C}$ until used or stored at $-20^{\circ} \mathrm{C}$. The membrane fractions were rich in menaquinones, whereas cytoplasmic fractions contained only trace amounts which were attributable to unsedimented membrane fragments. All subsequent work was with crude membrane fractions.

Menaquinone extraction. Menaquinones were extracted from $1 \mathrm{ml}$ of membrane preparation by a modified method of Kroger \& Dad'ak (1969), using $3.6 \mathrm{ml}$ methanol and $2.4 \mathrm{ml}$ petroleum ether in light-protected $15 \mathrm{ml}$ glass centrifuge tubes. The mixtures were shaken intermittently for $15 \mathrm{~min}$ at room temperature. Acetone $(1 \mathrm{ml})$ was added and shaking was continued for $15 \mathrm{~min}$. The upper layer was recovered after centrifugation $(1400 \mathrm{~g}$ for $5 \mathrm{~min}$ ) and the residue reextracted with $1 \mathrm{ml}$ petroleum ether. The combined extracts were evaporated to dryness prior to menaquinone purification.

Thin-layer chromatography $(T L C)$. Authentic standards and membrane-extracted menaquinones in acetone $(5 \mu l)$ were separated on C-18 reverse-phase thin-layer plates (Analtech, Newark, Del., U.S.A.) with a solvent system of methanol/acetone $(50: 50, \mathrm{v} / \mathrm{v})$. Development was complete in approximately $20 \mathrm{~min}$; separated menaquinones were detected with $254 \mathrm{~nm}$ UV light.

High performance liquid chromatography (HPLC). Authentic standards and membrane-extracted menaquinones were dissolved in acetone and separated by HPLC using a Waters System 272 equipped with a U6K injector (Waters Associates, Inc., Milford, Mass., U.S.A.) and a model 1305 variable-wavelength detector (Bio-Rad). An RCM-100 radial compression module fitted with a Radial Pak A C-18 reverse-phase $10 \mu \mathrm{m}$ column (Waters) was used in the separation. Menaquinones were chromatographed in a methanol/isopropanol $\left(75: 25, \mathrm{v} / \mathrm{v} ; 2 \mathrm{ml} \mathrm{min}{ }^{-1}\right)$ isocratic solvent system at room temperature. The eluent was monitored at $269 \mathrm{~nm}$ and collected. Purity of isolated menaquinones was determined by re-chromatography with HPLC and reverse-phase TLC.

UV absorption spectrophotometry. All spectroscopic measurements were made with a Cary 14 spectrophotometer (Applied Physics Corp., Monrovia, Ca., U.S.A.). Menaquinones purified by HPLC were evaporated to dryness and dissolved in absolute ethanol. Concentrations of menaquinone with six isoprene units (MK- 6 ) were determined by difference spectroscopy. A molar difference absorbance coefficient $(\Delta \varepsilon)$ of $22.8 \mathrm{~mm}^{-1} \mathrm{~cm}^{-1}$ was applied to MK-6 using wavelength pairs of 248-254 nm (Kroger et al., 1971); a coefficient was not determined for methyl-substituted MK-6. Reduction of menaquinones was achieved by the addition of $5 \mu \mathrm{l}$ of an aqueous solution of $\mathrm{KBH}_{4}\left(5 \mathrm{mg} \mathrm{ml}^{-1}\right.$, kept at $\left.0{ }^{\circ} \mathrm{C}\right)$ to $1 \mathrm{ml}$ of the ethanolic solution containing $5 \mu 10.5 \mathrm{M}$-sodium acetate buffer, pH $5 \cdot 2$ (Kroger \& Dad'ak, 1969).

Mass spectra. High- and low-resolution mass spectra were obtained using an AEI MS9 mass spectrometer with an acceleration potential of $8 \mathrm{kV}$ and electron ionization voltages of $70 \mathrm{eV}$ and $16 \mathrm{eV}$. The analyses were run at $220^{\circ} \mathrm{C}$ under computer control with an automatic data acquisition system. 


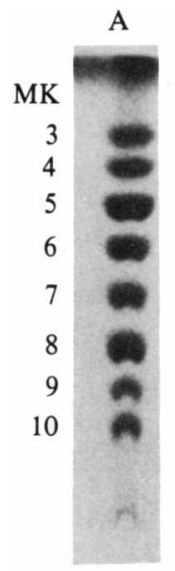

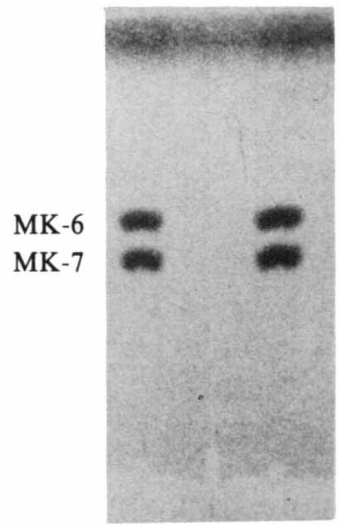

(a)

(b)

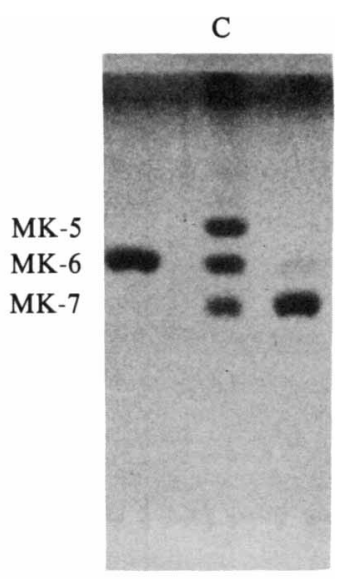

(a) (b) (c)

Fig. 1. Separation of authentic menaquinone standards and menaquinones from membrane extracts of Campylobacter jejuni and C. fetus subsp. fetus. Reverse-phase thin-layer chromatograms were developed in methanol/acetone $(50: 50, v / v)$. The chromatographic identities of menaquinones in $B$ and $C$ were based on $R_{F}$ values observed on chromatograph A (authentic menaquinone standards, MK-3 to MK10). B, menaquinones from membrane extracts of $(a) C$. jejuni and $(b) C$. fetus subsp. fetus. $C, C$. jejuni and $C$. fetus subsp. fetus menaquinones purified by HPLC: $(a)$ MK-6 from both species were mixed and chromatographed, $(b)$ authentic menaquinone standards MK-5, MK-6 and MK-7, and (c) methylsubstituted MK-6 from both species were mixed and chromatographed. Menaquinones were detected with $254 \mathrm{~nm}$ UV light.

Nuclear magnetic resonance (NMR) spectra. Proton magnetic resonance spectra were recorded on a Bruker highresolution multinuclear spectrometer at $500 \mathrm{MHz}$. Samples were dissolved in acetone- $d_{6}$ with tetramethylsilane as an internal standard. Chemical shifts are reported in parts per million (p.p.m.) downfield from tetramethylsilane.

Protein determination. Protein was determined by a modification of the Lowry method with bovine serum albumin as the standard (Dulley \& Greene, 1975).

\section{RESULTS}

Separation of menaquinones with reverse-phase TLC. The system used to establish chromatographic identity clearly and reproducibly resolved unsaturated menaquinones $\mathrm{MK}-3$ to $\mathrm{MK}-10$ (Fig. 1, A); no other authentic menaquinone standards were examined. Standard $R_{F}$ values decreased linearly as a function of increasing isoprene unit number, and the $R_{F}$ values ( $\times 100$ ) were as follows: MK-3, 82.7; MK-4, 75.9; MK-5, 68.5; MK-6, 59.9; MK-7, 50.0; MK-8, 40.0; MK-9, 30-2; and MK-10, 22-2. Membrane extracts from C. jejuni and C. fetus subsp. fetus contained menaquinones that co-chromatographed with authentic MK-6 and MK-7 standards in the methanol/acetone solvent system (Fig. 1, B) and in the less polar methanol/isopropanol and the more polar methanol/acetonitrile solvent system. The identity of MK- 6 extracted from membranes was verified for both organisms (details given below). In contrast, material identified chromatographically as MK-7 was found to be a methyl-substituted MK-6 (2,[5 or 8]dimethyl-3-farnesyl-farnesyl-1,4-naphthoquinone) with six unsaturated isoprene units. The methyl-substituted MK- 6 appeared to be less polar than MK-6, as indicated by the lower $R_{F}$ value. Mixtures of purified MK-6 from $C$. jejuni and $C$. fetus subsp. fetus were separated and found to develop as a discrete spot (Fig. 1, C); this was also observed with mixtures of methylsubstituted MK-6.

Separation of menaquiones by HPLC. Mixtures of authentic menaquinone standards (MK-4 to MK-9) were separated under isocratic conditions, and chromatographed as a function of isoprene unit number. All six menaquinone standards were separated within 25 min (Fig. 2). No significant difference in selectivity or sensitivity was found when menaquinones were monitored at $269 \mathrm{~nm}$ (quinonoid absorbance) or $248 \mathrm{~nm}$ (benzenoid absorbance). 

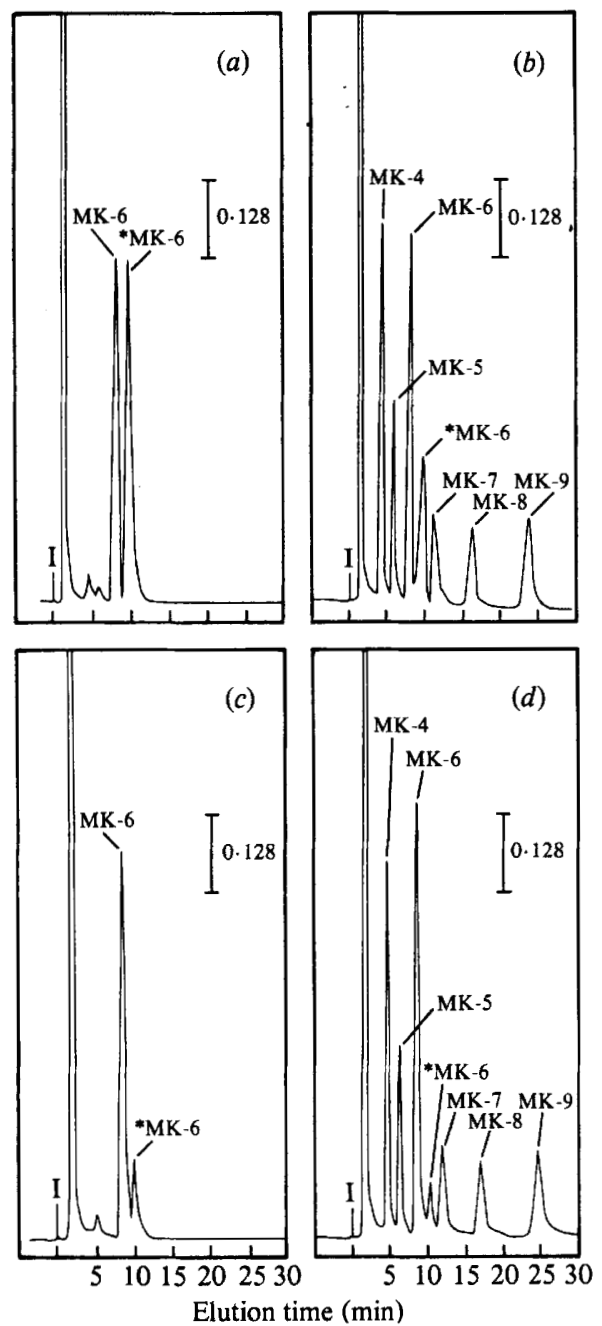

Fig. 2. High-performance liquid chromatograms of authentic menaquinone standards MK-4 to MK-9 and membrane-extracted menaquinones MK- 6 and methyl-substituted *MK-6, $(a, b)$ Membraneextracted menaquinones from Campylobacter jejuni $(a)$ alone and $(b)$ added to a mixture of authentic menaquinone standards, MK-4 to MK-9. $(c, d)$ Membrane-extracted menaquinones from $C$. fetus subsp. fetus $(c)$ alone and $(d)$ added to a mixture of authentic menaquinone standards, MK-4 to MK-9. Menaquinones from both $C$. jejuni and $C$. fetus subsp. fetus had elution times of 8.3 (MK- 6 ) and $10.0 \mathrm{~min}$ (methyl-substituted *MK-6). Menaquinones were separated with a Waters $\mathrm{C}-18$ reverse-phase radial compression cartridge using methanol/isopropanol $\left(75: 25, \mathrm{v} / \mathrm{v} ; 2 \mathrm{ml} \mathrm{min}^{-1}\right)$ isocratically at room temperature. The eluent was monitored at $269 \mathrm{~nm}$. Menaquinones MK-4 to MK- 9 were resolved at the elution times of $4 \cdot 5,6 \cdot 3,8 \cdot 3,11 \cdot 8,16 \cdot 8$ and $24 \cdot 1 \mathrm{~min}$, respectively. Bar, absorbance unit; I, injection point.

Two major menaquinones, one which co-chromatographed with MK-6 and the other between MK-6 and MK-7 standards, were detected in both species of Campylobacter (Fig. 2). The peak eluting at $8.3 \mathrm{~min}$ was verified as a MK-6, and the peak eluting at $10.0 \mathrm{~min}$ was verified as that of methyl-substituted MK-6 (2,[5 or 8]-dimethyl-3-farnesyl-farnesyl-1,4-naphthoquinone) with six unsaturated isoprene units (details given below). From the relative peak heights in Fig. 2(a) it appeared that the two menaquinones extracted from $C$. jejuni were produced in approximately equal amounts (assuming that both menaquinones were extracted and separated with similar efficiencies), whereas $C$. fetus subsp. fetus had approximately five times more MK-6 than methyl-substituted MK-6 (Fig. 2c). 


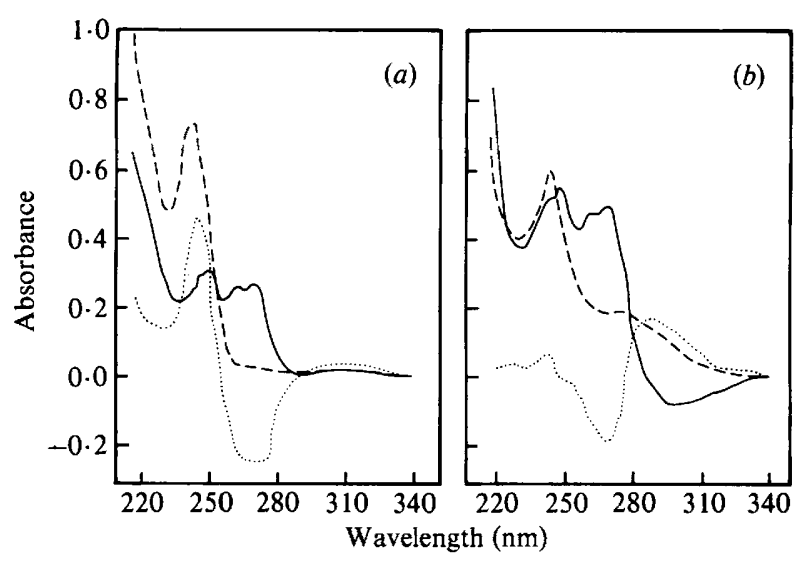

Fig. 3. UV absorption spectra of menaquinones in absolute ethanol. (a) MK- 6 and (b) methylsubstituted MK-6. ___, Oxidized menaquinones; --.-, reduced menaquinones obtained after reduction of solution $a, \ldots .$. , difference spectra of menaquinones (reduced vs oxidized) obtained with oxidized sample in reference cuvette and reduced sample in sample cuvette. Menaquinones were reduced by adding $5 \mu \mathrm{l}$ of an aqueous solution of $\mathrm{KBH}_{4}\left(5 \mathrm{mg} \mathrm{ml}^{-1}\right)$ to $1 \mathrm{ml}$ of the ethanolic solution, which contained $5 \mu \mathrm{l} 0.5 \mathrm{M}$-sodium acetate buffer ( $\mathrm{pH} 5 \cdot 2$ ).

UV absorption spectra of menaquinones. UV spectra of ethanolic solutions of menaquinone purified from Campylobacter were recorded at room temperature from 220 to $340 \mathrm{~nm}$ (Fig. 3). Menaquinone-6 in $C$. jejuni was present at approximately $3.5 \mu \mathrm{mol}$ (g membrane protein $)^{-1}$, whereas in $C$. fetus subsp. fetus MK-6 was approximately $2 \cdot 3 \mu \mathrm{mol}$ (g membrane protein) ${ }^{-1}$.

The maxima for oxidized MK- 6 and methyl-substituted MK- 6 were at 242 and $248 \mathrm{~nm}$ (benzenoid absorbance) and 261 and $269 \mathrm{~nm}$ (quinonoid absorbance) (Fig. 3, solid lines). Upon reduction (dashed lines), the MK- 6 spectrum changed to one characteristic of a hydroquinone (substantial loss of absorption bands at 261 and $269 \mathrm{~nm}$ and increased intensity at $245 \mathrm{~nm}$ ), whereas the methyl-substituted MK-6 spectrum appeared as an intermediate to that of the reduced MK-6 spectrum. The absorption loss at 261 and $269 \mathrm{~nm}$ was not complete, and there was little increase at $245 \mathrm{~nm}$. Isosbestic points of the difference spectra for MK-6 were at 254 and $288 \mathrm{~nm}$ and for methyl-substituted MK-6 at 250 and $275 \mathrm{~nm}$ (Fig. 3, dotted lines). The maximum absorbance decrease for both MK- 6 and methyl substituted MK- 6 occurred 2 min after reduction and remained constant for up to $1 \mathrm{~h}$. Addition of more $\mathrm{KBH}_{4}$ and/or acetate buffer, to ensure complete reduction of substituted MK- 6 , resulted in little change of the absorption.

Mass spectrometry. The molecular ions $\left(\mathrm{M}^{+}\right)$for MK- 6 and methyl-substituted MK- 6 were at mass-to-charge ratios ( $m / e$ ) of 580 and 594, respectively (Fig. 4). Fragmentation peaks for MK-6 (Fig. $4 a$ ) were at $m / e 580\left(\mathrm{M}^{+}\right), 511,443,375,307,239,225$ and 187. For methyl-substituted MK-6 (Fig. 4b), peaks were at $m / e 594\left(\mathrm{M}^{+}\right), 525,457,389,321,253,239$ and 201. Fragmentation of the polyprenyl side chains showed the loss of the terminal isoprenyl unit (69 mass units) followed by successive losses of 68 mass units. Saturation of olefinic bonds within the side chain was not observed. In Fig. $4(b) R$ and $R_{1}$ represent a methyl group and a proton, not necessarily respectively (details given below).

NMR spectroscopy. Table 1 and Fig. 5 summarize the data obtained from the $500 \mathrm{MHz}$ proton NMR spectra of MK-6 and methyl-substituted MK-6.

\section{DISCUSSION}

Campylobacter jejuni and C. fetus subsp. fetus contained two respiratory quinones, a menaquinone-6 (2-methyl-3-farnesyl-farnesyl-1,4-naphthoquinone) and a methyl-substituted menaquinone-6 (2,[5 or 8]-dimethyl-3-farnesyl-farnesyl-1,4-naphthoquinone). Mass spectro- 

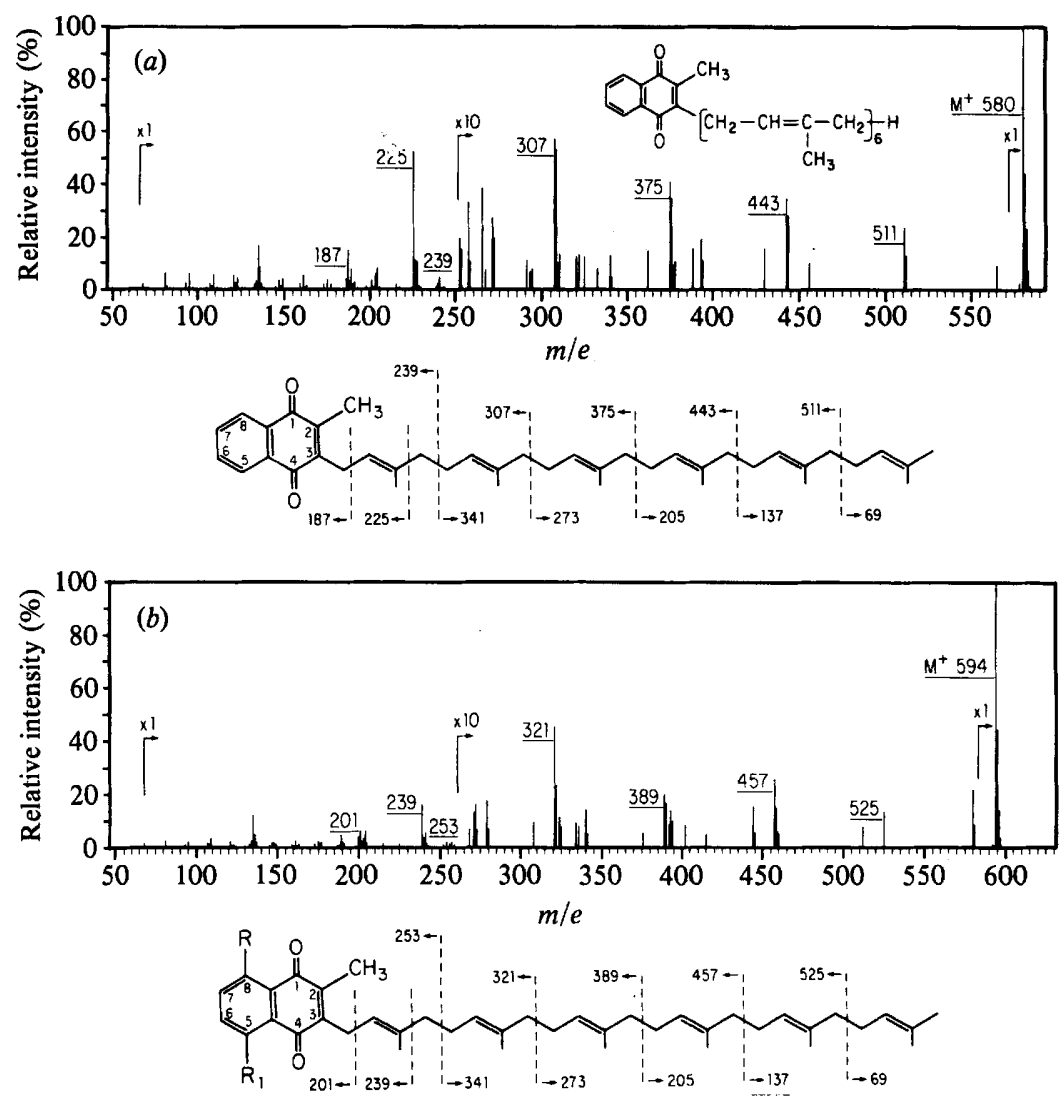

Fig. 4. Mass spectra and chemical structures of membrane-extracted menaquinones. Spectra and structures of $(a)$ MK- 6 and $(b)$ methyl-substituted MK-6. In the chemical structures shown in $(b), \mathbf{R}$ and $\mathbf{R}_{1}$ are a methyl group and a proton in the peri position (not necessarily respectively). The molecular ion $\left(\mathrm{M}^{+}\right)$for MK-6 was at $m / e 580$ and for methyl-substituted MK-6 at $m / e$ 594. The fragmentation pattern of the proprenyl side chains showed the loss of the terminal isoprenyl unit (69 mass units) followed by successive losses of 68 mass units. Olefinic bonds in the polyprenyl side chain were unsaturated. Analysis was made with an acceleration potential of $8 \mathrm{kV}$ and ionization potential of $16 \mathrm{eV}$ at $220^{\circ} \mathrm{C}$.

metry and NMR spectra of substituted MK-6 indicated that a methyl substituent was located on the naphthoquinone nucleus (C-5 or C-8) and that the polyprenyl side chain was unsaturated. To assign the methyl group it will be necessary to synthesize appropriate model compounds and to carry out NMR spectral comparisons.

The NMR spectrum and chemical shift assignments of MK-6 (Table 1) corresponded to other menaquinone isoprenologues obtained by previous workers (Langemann \& Isler, 1965; Thomson, 1971). The menaquinones had almost symmetrically substituted naphthoquinone moieties so that the two peri aromatic protons $(\mathrm{H}-5$ and $\mathrm{H}-8)$ had nearly the same chemical shifts as one another. The same situation also applied to the other two aromatic protons ( $\mathrm{H}-6$ and $\mathrm{H}-7)$. The spectrum of the methyl-substituted MK-6 (Table 1) was very similar to that of MK-6, except for the aromatic proton region, where there was only three protons instead of four. The splitting pattern of the aromatic protons in methyl-substituted MK-6 (Fig. 5) revealed that the substituent was a methyl group in a peri position on the aromatic ring. This methyl group caused a shielding of the three aromatic protons $\left(\mathrm{H}_{1}, \mathrm{H}_{2}\right.$, and $\left.\mathrm{H}_{3}\right)$, with the ortho proton $\left(\mathrm{H}_{3}\right)$ the most shielded.

The assignments of the aromatic protons were made on the basis of a large $(7.5 \mathrm{~Hz})$ ortho coupling constant in the signal of $\mathrm{H}_{1}$ and $\mathrm{H}_{3}$, and two such coupling constants in the signal of $\mathrm{H}_{2}$. In addition, the deshielded proton signal at $\delta 7.97$ clearly corresponded to a peri proton. 


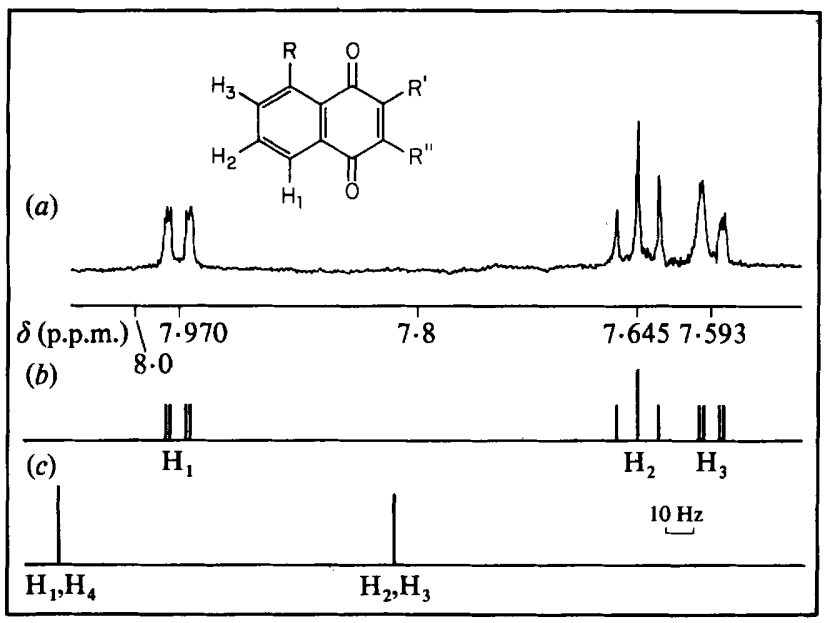

Fig. 5. Partial proton NMR spectra of menaquinones. (a) Experimental spectrum of methylsubstituted MK-6 $(\mathbf{R}=$ methyl) in the aromatic proton region. $(b)$ Theoretical first-order spectrum corresponding to $(a)$, but without long-range coupling to the benzenoid $(R)$ methyl group $\left(J_{1,2}=J_{2,3}=7.5 \mathrm{HZ} ; J_{1,3}=2 \mathrm{~Hz}\right.$ ). (c) Chemical shifts (mean of $\mathrm{H}_{1}$ and $\mathrm{H}_{4}$ and mean of $\mathrm{H}_{2}$ and $\left.H_{3}\right)$ for the aromatic protons in $M k-6\left(R=H_{4}\right)$. In the structure shown, $R^{\prime}$ and $R^{\prime \prime}$ are methyl and polyprenyl groups (not necessarily respectively).

\section{Table 1. Chemical shifts and splitting patterns for the NMR spectra of menaquinone-6 and methyl-substituted menaquinone-6}

Chemical shifts $(\delta)$ are given as p.p.m. downfield from tetramethylsilane in deuterated acetone- $d_{6}$. Splitting patterns are denoted as follows: s, singlet; bs, broad singlet (line at half peak height about 3 to $4 \mathrm{~Hz}$ ) $\mathrm{d}$, doublet; $\mathrm{t}$, triplet; and $\mathrm{m}$, multiplet arising from two or more chemical shifts as well as from spin-spin coupling.

\begin{tabular}{|c|c|c|c|c|}
\hline & \multicolumn{2}{|c|}{ Menaquinone-6 } & \multicolumn{2}{|c|}{ Substituted menaquinone- 6} \\
\hline & $\delta$ (p.p.m.) & Pattern & $\delta$ (p.p.m.) & Pattern \\
\hline Methyl groups (trans to olefinic-H) & $\begin{array}{l}1.544 \\
1.560 \\
1.584 \\
1.592^{*}\end{array}$ & $\begin{array}{l}\text { bs } \\
\text { bs } \\
\text { bs } \\
\text { bs }\end{array}$ & $\begin{array}{l}1.534 \\
1.547 \\
1.575 \\
1.581^{*}\end{array}$ & $\begin{array}{l}\text { bs } \\
\text { bs } \\
\text { bs } \\
\text { bs }\end{array}$ \\
\hline End-of-chain methyl (cis to olefinic-H) & 1.650 & bs & 1.640 & bs \\
\hline Methyl (1st isoprene unit) & $1 \cdot 816$ & bs & $1 \cdot 794$ & bs \\
\hline Allylic $\mathrm{CH}_{2}$ groups & $1 \cdot 944-2 \cdot 030$ & $\mathrm{~m}$ & $1 \cdot 889-2 \cdot 025$ & $\mathrm{~m}$ \\
\hline Benzenoid methyl & - & - & -+ & - \\
\hline Quinonoid methyl & $2 \cdot 184$ & $\mathbf{s}$ & $2 \cdot 165$ & $\mathrm{~s}$ \\
\hline Bisallylic $\mathrm{CH}_{2}$ & 3.405 & $\mathrm{~d} \ddagger$ & $3 \cdot 356$ & $d \ddagger$ \\
\hline Olefinic $\mathrm{CH}$ groups & $5 \cdot 028-5 \cdot 152$ & $\mathrm{~m}$ & $5 \cdot 016-5 \cdot 120$ & $\mathrm{~m}$ \\
\hline Aromatic-H (C-6, C-7) & $7 \cdot 82 \S$ & $\mathrm{m}$ & $\begin{array}{l}7 \cdot 593 \\
7 \cdot 645\end{array}$ & $\begin{array}{l}d \| \\
t \|\end{array}$ \\
\hline Aromatic-H (C-5 and/or C-8) & $8.06 \S$ & $\mathrm{m}$ & 7.970 & $\mathrm{~d} \|$ \\
\hline \multicolumn{5}{|c|}{$\begin{array}{l}\text { * Intensity corresponds to two methyl groups. } \\
\dagger \text { The benzenoid methyl group was obscured by solvent lines }\left(\mathrm{CD}_{3} \mathrm{COCHD}_{2}\right) \text {. } \\
\ddagger J\left(\mathrm{CH}_{2} \text {-olefinic-H }\right)=7 \cdot 0 \mathrm{~Hz} \text {. } \\
\S \text { Mean chemical shift. } \\
\text { ॥ Pattern caused by } J_{\text {ortho }}(7 \cdot 5 \mathrm{~Hz}) \text {. }\end{array}$} \\
\hline
\end{tabular}

This was consistent with aromatic chemical shifts in MK-6 (Fig. 5) and the known shielding effects of a methyl group on aromatic protons (Jackman \& Sternhell, 1969). Also consistent with this assignment was the presence of a small $(2 \mathrm{~Hz})$ meta coupling of $\mathrm{H}_{1}$ with $\mathrm{H}_{3}$. In the case of $\mathrm{H}_{3}$, the splitting was obscured by the presence of an expected long-range coupling to the methyl group (Jackman \& Sternhell, 1969). Because of the solvent (acetone- $d_{6}$ ) used in the NMR 
measurement, the methyl group on the aromatic ring was not directly visible in the NMR spectrum of substituted MK- 6 . However, the evidence presented unambiguously defined the peri placement of this group, although a differentiation between the two peri positions was not possible.

The intermediate reduction observed with UV absorption spectrometry may have resulted from incomplete quinone reduction. Electron-donating groups such as methyl and hydroxy tend to stabilize the oxidized (quinone) form of the naphthoquinone nucleus relative to the reduced (hydroquinone) form (Streitwieser \& Heathcock, 1976). The electron-rich menaquinone, therefore, is not easily reduced and results in a lowering of the redox potential; the opposite effect is observed with electron-attracting groups. The methyl of substituted MK-6 (C-5 or C-8) probably stabilized the quinone and made it less easily reduced. This probably made the redox potential of substituted MK-6 lower than that of MK-6. A difference in redox potential may allow the menaquinones to participate in diverse cellular processes.

Separation of menaquinones by reverse-phase TLC is based primarily on the length and degree of unsaturation (Collins et al., 1980; Collins \& Jones, 1981; Dunphy \& Brodie, 1971). However, when comparing $R_{F}$ values of MK and DMK having the same polyprenyl side chain length, the addition of a methyl group to C-2 of DMK results in a decreased $R_{F}$ value (Dunphy \& Brodie, 1971). In this study, the substitution of a second methyl group on C-5 or C-8 of MK-6 also decreased the $R_{F}$ value. With the solvent systems used for reverse-phase TLC, methylsubstituted MK-6 was not adequately separated from MK-7, whereas with reverse-phase HPLC, both were separated.

Menaquinone identity may be ambiguous when only reverse-phase TLC and UV spectrophotometry are used for identification. Additional techniques were required to characterize the novel quinone found in this study. Substituted MK- 6 as well as other substituted menaquinone isoprenologues may, therefore, be more prevalent than reported to date, since many earlier studies have relied solely upon reverse-phase TLC and UV spectrophotometry. For accurate menaquinone identification, reverse-phase HPLC, UV spectrophotometry, mass spectroscopy and NMR analyses are needed.

Preliminary extraction and reincorporation experiments with $C$. jejuni and $C$. fetus subsp. fetus indicated that MK- 6 and methyl-substituted MK- 6 are obligatory components of the NADH : fumarate oxidoreductase system. An investigation of the hydrogen-fumarate and formate-fumarate oxidoreductase systems is in progress.

We are indebted to Dr June Lascelles for providing the means for this study and for her encouragement and invaluable criticism in writing the manuscript. We thank Dr James A. Sadowski, School of Dentistry, Marquette University for providing the authentic menaquinone standards. Thanks are due to Dr Joseph T. Barbieri for his expert advice on HPLC and to Dr Stephen F. Carroll for his advice on reverse-phase TLC. We also thank the Southern California Regional Nuclear Magnetic Resonance Facility (California Institute of Technology, Pasadena, Ca.) and the University of Los Angeles Mass Spectroscopy Laboratory for the use of their Bruker $500 \mathrm{MHz}$ and AEI MS9 spectrometers, respectively.

\section{REFERENCES}

Bentley, R. \& Meganathan, R. (1982). Biosynthesis of vitamin $\mathrm{K}$ (menaquinone) in bacteria. Microbiological Reviews 46, 241-280.

Carlone, G. M. \& Lascelles, J. (1982). Aerobic and anaerobic respiratory systems in Campylobacter fetus subsp. jejuni grown in atmospheres containing hydrogen. Journal of Bacteriology 152, 306-314.

Collins, M. D. \& Jones, D. (1981). Distribution of isoprenoid quinone structural types in bacteria and their taxonomic implications. Microbiological Reviews 45, 316-354.

Collins, M. D., Shah, H. N. \& Minnikin, D. E. (1980). A note on the separation of natural mixtures of bacterial menaquinones using reverse phase thin- layer chromatography. Journal of Applied Bacteriology 48, 277-282.

Dulley, J. R. \& Greene, P. A. (1975). A simple technique for eliminating interference by detergents in the Lowry method of protein determination. Analytical Biochemistry 64, 136-141.

DunPhy, P. J. \& Brodie, A. F. (1971). The structure and function of quinones in respiratory metabolism. Methods in Enzymology 18, 407-461.

HARVEY, S. \& LASCELles, J. (1980). Respiratory systems and cytochromes in Campylobacter fetus subsp. intestinalis. Journal of Bacteriology 144, 917922.

HoffMan, P. S. \& Goodman, T. G. (1982). Respiratory 
physiology and energy conservation efficiency of Campylobacter jejuni. Journal of Bacteriology 150, 319-326.

Hollander, R. (1981). The dependence on quinone specificity of terminal electron transport of bacteria. Current Microbiology 6, 155-159.

JACKMAN, L. M. \& STERNHELL, S. (1969). Long-range interproton coupling. In Applications of Nuclear Magnetic Resonance Spectroscopy in Organic Chemistry, vol. 5, pp. 312-344. Edited by D. H. R. Barton \& W. Doering. New York: Pergamon Press.

KROGER, A. (1980). Bacterial electron transport to fumarate. In The Diversity of Bacterial Respiratory Systems, vol. 2, pp. 1-17. Edited by C. J. Knowles. Boca Raton, Florida: CRC Press.

KRoger, A. \& DAD'AK, V. (1969). On the role of quinones in bacterial electron transport - the respiratory system of Bacillus megaterium. European Journal of Biochemistry 11, 328-340.

Kroger, A., DAD'AK, V., KlingenberG, M. \& DIEMER, F. (1971). On the role of quinones in bacterial electron transport - differential roles of ubiquinones and menaquinones in Proteus rettgeri. European Journal of Biochemistry 21, 322-333.

LangemanN, A. \& IsleR, O. (1965). Chemistry of isoprenoid quinones. In Biochemistry of Quinones, vol. 1, pp. 89-147. Edited by R. A. Morton. New York: Academic Press.

SMIBERT, R. M. (1981). The genus Campylobacter. In The Prokaryotes, pp. 609-617. Edited by M. P. Starr, H. Stolp, H. G. Truper, A. Balows \& H. G. Schlegel. New York: Springer-Verlag.

Streitwieser, A., JR \& Heathcock, C. H. (1976). Phenols, phenyl ethers and quinones. In Introduction to Organic Chemistry, pp. 998-1036. New York: Macmillan.

TABER, H. (1980). Functions of vitamin $\mathrm{K}_{2}$ in microorganisms. In Vitamin $K$ Metabolism and Vitamin K-dependent Proteins, pp. 177-187. Edited by J. W. Suttie. Maryland: University Park Press.

Taber, H. W., Sugarman, B. J. \& Halfenger, G. M. (1981). Involvement of menaquinones in the active accumulation of aminoglycosides by Bacillus subtilis. Journal of General Microbiology 123, 143-149.

Thauer, R. K., Jungermann, K. \& Decker, K. (1977). Energy conservation in chemotrophic anaerobic bacteria. Bacteriological Reviews 41, 100-180.

ThOMSON, R. H. (1971). Identification. In Naturally Occurring Quinones, 2nd edn. pp. 39-92. New York: Academic Press. 